Review

\title{
Antibody Fragments Defining Biologically Relevant Conformations of Target Proteins
}

\author{
Alastair D. G. Lawson \\ UCB, 216 Bath Road, Slough, SL1 3WE UK; E-Mail: alastair.lawson@ucb.com \\ External Editor: Tsutomu Arakawa
}

Received: 10 November 2014; in revised form: 2 December 2014 / Accepted: 8 December 2014 / Published: 11 December 2014

\begin{abstract}
Antibody fragments have long been used as chaperones in crystallography, but have more recently been applied to the definition of biologically relevant conformations among the dynamic ensemble of target protein conformational sampling. This review charts the progress being made in understanding function in the context of structure using this approach, and highlights new opportunities for drug discovery.
\end{abstract}

Keywords: antibody fragments; conformation; definition

\section{Introduction}

Antibody fragments have been used as chaperones to aid crystallization and enable structure-determination of target proteins for many years [1], from the first application of:

- a Fab fragment to the crystallization of whale N9 neuraminidase in 1987 [2],

- an Fv fragment to the crystallization of bacterial cytochrome $c$ oxidase in 1995 [3],

- and a VHH fragment to the crystallization of the intrinsically flexible addiction antidote MazE in 2003 [4],

to recent publications, such as the structure-determination of the mouse serotonin 5-HT3 receptor [5].

Desirable properties attributed to antibody fragments in these applications include:

- rigidifying complexes [6],

- enhancing solubility [7],

- breaking intrinsic self-polymerising propensity [8],

- contributing packing contacts within the crystal lattice [5], 
- widening the crystallisation space [9],

- enabling molecular replacement in analysis and providing initial model-based phasing information $[10,11]$.

Antibody fragments continue to be widely used as essential tools in crystallography, but it has become clear that their utility extends beyond the properties outlined above to encompass definition of specific, biologically relevant conformations of target proteins, enabling all-important connections to be established between structure, function and clinical validation. In this new role, broad application of antibody fragments as tools to 'lock out' validated conformations of target proteins is leading to exciting opportunities in drug discovery from Neuroscience to Immunology, and the pioneering work of Brian Kobilka on the $\beta_{2}$ adrenergic receptor and Jan Steyaert with single domain VHH (nanobody) antibody technology deserves special mention.

\section{Definition of Functionally Relevant Conformations of Proteins}

For many years there had been an appreciation that ligands induce different functions through stabilisation of distinct conformations, for example with GPCRs (G protein coupled receptors) [12]. Early structural insights into function had to contend with the inherent flexibility and instability of the intracellular loop 3 in detergent solutions of, for example, the $\beta_{2}$ adrenoceptor, and this issue was addressed by substitution with T4 lysozyme [13] and with an Fab fragment [14]. By 2009, firm links were starting to be made between Fab fragments acting as chaperones in stabilising structures in crystallography and their utility in defining clinically important conformations of proteins; for example the first crystal structure of the physiologically relevant closed conformation of the proton-activated, voltage-modulated $\mathrm{K}^{+}$channel KcsA, enabled by a synthetic Fab fragment, was published at this time [15].

Nevertheless it was clear that more challenging, high resolution structures of receptor complexes with agonists and accessory proteins, as well as methods to address inherent dynamics, would be needed to gain a full understanding of mechanisms of action, and that antibody fragments would play a key role in this quest.

Proteins naturally sample an ensemble of conformations, representing different energy states arising from intramolecular interactions. Functionally distinct ligands shift the equilibrium of the energy landscape, by lowering the energy barriers separating active and inactive states, to stabilise specific conformations, thereby promoting specific interactions with downstream binding partners and giving rise to specific functions [16,17]. Basal activity, in the absence of ligand, results from brief, inefficient sampling of active conformations, and agonist-binding is often insufficient per se to stabilise a signalling state. Indeed, agonist-binding alone commonly increases conformational heterogeneity [18], providing a significant technical challenge to obtaining crystal structures of active states. In general the most thermodynamically stable conformations predominate in time, such that crystallisation often captures these states and provides merely a snapshot of the dynamic ensemble of physiologically relevant conformations [19,20].

Antibody fragments, which modify function, particularly through binding at allosteric sites, offer considerable potential to 'freeze the frame' on the dynamic movie and provide valuable structural information relating to specific target function [21]. Full length antibodies have been used, for example to probe conformational states associated with photoactivation of rhodopsin [22], and activation-dependent conformational changes in the $\mathrm{N}$ terminus of the $\mu$-opioid GPCR [23]. More recently this area has 
expanded dramatically with the application of antibody fragments defining conformational states in crystallographic studies. For example Fab fragments, VHH fragments as well as Fynomers have been used to define an ensemble of low energy conformations available to the BACE2 aspartic protease, a drug target in diabetes [24].

The seminal paper from Brian Kobilka's group in 2011, in which the $\beta_{2}$ adrenoceptor was crystalized in an active state [25] represents one of the landmark publications in the field (Figure 1).

Figure 1. Crystal structure of a nanobody-stabilized active state of the $\beta_{2}$ adrenoceptor (PDB 3POG).

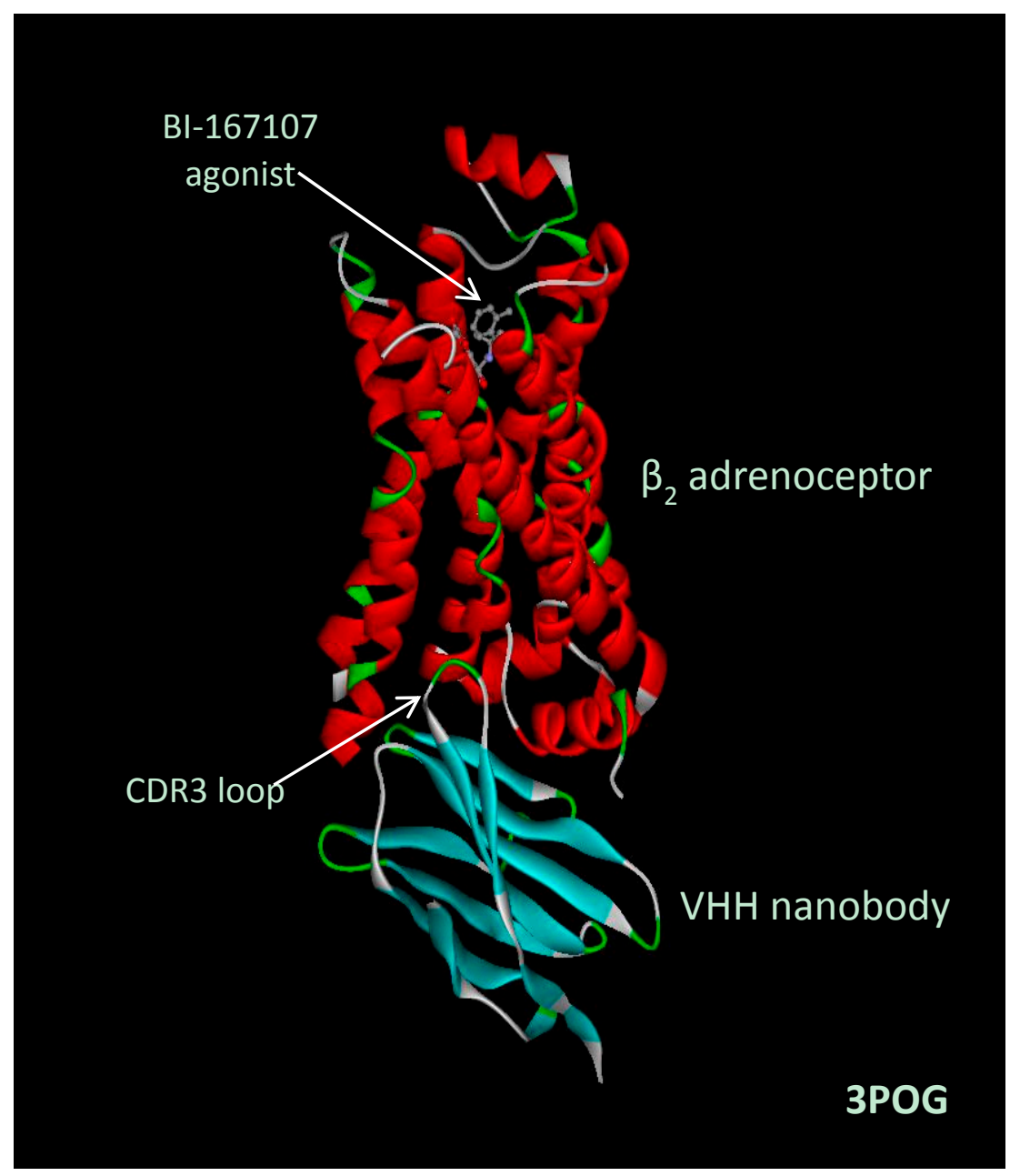

Even when bound by a covalent agonist, the $\beta_{2}$ adrenoceptor crystallised in an inactive conformation [26], and definitive switching to the active state was thought to require binding of both agonist and $\mathrm{G}$ protein, Gs, to overcome inherent, spontaneous relaxation. As working with Gs entailed considerable biochemical challenge, a specific, single domain antibody fragment (VHH or nanobody) was used as a surrogate $G$ protein to stabilise the active conformation and enable a crystal structure to be obtained. In a follow-on paper later in 2011, the same group described the structure of a T4 lysozyme-engineered- $\beta_{2}$ adrenergic receptor-Gs complex [27]. The overall structure of the GPCR was remarkably similar to the nanobody-stabilised version, validating the use of antibody fragments, with functional similarity to known binding partners, in defining specific, biologically relevant conformations of target proteins.

The crystal structure of the $\mathrm{A}_{2 \mathrm{~A}}$ adenosine receptor has also been determined, but this time in an inactive conformation, and by stabilisation with a specific Fab fragment [28]. The antibody trapped a 
conformation, which prevented agonist but not antagonist binding to the extracellular ligand-binding pocket, allosterically, through binding to the intracellular face. Interestingly the complementarity-determining region, CDR3 H3 loop, of the Fab fragment penetrated deep into the GPCR, mimicking the CDR3 of the VHH in the Rasmussen paper [25], and showing that extended CDR loops are not the sole preserve of nanobodies.

While GPCRs have been the focus of much of the pioneering work with antibody fragment-definition of conformations, a new perspective on $\operatorname{IgE}$ function in allergen recognition has been achieved through study of a diversity of conformational states [29]. A function-modifying antibody Fab fragment was shown to hold the $\mathrm{C} \varepsilon 2$ and $\mathrm{C} \varepsilon 3$ domains in a linear structure which precluded receptor binding, validating molecular dynamics predictions of IgE Fc conformational sampling. Insight into the gating mechanism of a bestrophin calcium-activated chloride channel has also been achieved with an Fab fragment, which preferentially recognised the calcium-bound, open form of the pentamer, and supported ion flux [30].

As well as providing valuable information about conformations of individual target proteins, antibody fragments have such broad applicability, that they have, for example, revealed subtle mechanistic details in $\mathrm{T}$ cell biology, showing that L-plastin contributes to immune synapse formation through specific interactions with LFA-1 [31].

\section{Links to the Design of Therapeutics}

More recently the structure of an agonist-bound, active state of the human $\mathrm{M}_{2}$ muscarinic acetylcholine receptor, stabilised by a G-protein mimetic VHH antibody fragment, has been published [32]. The Nb9-8 nanobody bound to the intracellular region, again with a CDR loop protruding between the alpha helices. Compared to rhodopsin and $\beta_{2}$ adrenoceptor, a similar outward rotation of transmembrane domain 6 was seen, to create a G-protein-binding cavity on the intracellular surface. However more profound changes in the orthosteric binding site and in the extracellular vestibule have been revealed with the $\mathrm{M}_{2}$ receptor, providing concomitant opportunities for the development of novel therapeutics [33]. In particular, contraction of the orthosteric site in the active state contrasted with the large orthosteric site of the inactive conformation, informing the chemistry of agonists (better suited by low molecular weight compounds) and antagonists and inverse agonists, for which higher molecular weights could be accommodated. Similarly the extracellular vestibule was significantly smaller in the active conformation, even in the absence of bound allosteric modulator. Such insights, provided from antibody fragment-stabilised structures are providing new opportunities for drug discovery, particularly in the design of positive and negative allosteric modulators of GPCRs.

In diabetes research, a previously unrecognised inhibitory activity of the extracellular domain of the glucagon receptor was revealed in a Fab-stabilised crystal structure, where the antibody fragment acted as an inverse agonist [34]. The third extracellular loop was implicated in glucagon-mediated structural changes accompanying receptor activation, and this insight opens new possibilities for design of novel allosteric regulators addressing Class B GPCR-related diseases.

In oncology, development of imaging agents and therapeutics targeting the epidermal growth factor receptor (EGFR) is being aided by an appreciation of the modes of action of allosteric VHH fragments. Antibody fragments, which prevent the receptor conformational changes required for high affinity ligand 
binding and dimerization, are particularly valuable tools for highlighting previously unknown mechanisms for intervention [35]. Nanobodies are also being used to probe changes in the size and shape of the P-glycoprotein (P-gp) pocket during the course of the transport cycle [36]. P-gp is a key mediator of efflux-based multidrug resistance, and nanobodies which inhibit ATP hydrolysis by hindering formation of a critical dimeric state can shed new light on possible therapeutic strategies.

Conformational definition of intracellular proteins is also within the scope of antibody fragment tools. Intracellularly-expressed single domain antibody fragments, which block downstream effector interactions or stabilise specific receptor conformations are proving to be useful tools in probing complex GPCR biology [37]. Similarly conformation-specific nanobodies are beginning to be used as biosensors, showing canonical GPCR signalling from endosomes as well as plasma membranes, and indicating that internalised receptors contribute to signalling [38]. Such antibody fragments may eventually hold therapeutic potential once the challenges posed by gene delivery have been successfully addressed. In the meantime, their primary application will be in aiding small molecule discovery.

With another target in diabetes and obesity, protein tyrosine phosphatase 1B (PT1B), intracellular expression of conformation-selective scFv fragments, which stabilised the oxidised, inactive form of the enzyme, was demonstrated to enhance the effects of insulin, offering new insight into phosphatase drug development [39].

In HIV research, mapping the interface of an intracellularly expressed VHH fragment, which blocked multimerisation of the Rev protein, presents a starting point for rational design of small molecules mimicking the antibody's ability to interfere with protein-protein interactions of the Rev N-terminal domain [40].

Antibody fragments are also highlighting the potential for discovery of small molecules capable of interfering with the invasion machinery of Plasmodium falciparum. A crystal structure of a nanobodyvalidated conformation of the myosin-binding D3 domain of the myosin tail interacting protein (MTIP) revealed a new format, in which the myosin A binding groove was less accessible due to movement of two helices [41]. Small molecules, partly based on a critical contact residue of the VHH and elaborated to occupy the myosin A binding groove, may be expected to hinder myosin A binding by maintaining the conformation defined by the nanobody.

As well as guiding on-target drug discovery research, antibody fragments are shedding light on the avoidance of off-target effects of drugs such as gefitinib. For example, rational design of kinase inhibitors, to avoid respiratory side effects associated with cyclin G-associated kinase (GAK) binding, has been aided by antibody fragment-definition of dimeric (inactive) and monomeric (active) states of the GAK catalytic domain [42].

Vaccine design is also being improved through study of newly revealed sites, for example in the Respiratory Syncytial Virus (RSV) [43]. Metastability of the RSV Fusion (F) glycoprotein has hampered characterisation of the protein, but the structure of a pre-fusion state, revealed by specific, neutralising antibody Fab fragments, has provided new insight. The D25 antibody locked F in its prefusion state by binding to the trimer apex; interestingly this was achieved by co-expression of an F protein construct with the D25 Fab fragment. Vaccine antigens, stabilised in the antibody-defined pre-fusion conformation through, for example, disulphide bond engineering, may help to focus immune responses to antibodyvalidated sites of vulnerability. 


\section{Definition of Intermediate Conformations in Disease Processes Offering New Opportunities for Therapy}

Parallel advances, with antibody fragments defining unstable, early stage intermediate structures in fibrillogenic pathways and protein deposition diseases, have also been reported. As early as 2003, a VHH fragment to human lysozyme was shown to inhibit in vitro aggregation of the amyloidogenic variant, $\mathrm{D} 67 \mathrm{H}$, through transmission of long-range conformational effects to the inter-domain interface [44].

At the same time that VHH fragments were being applied to lock the active state of the $\beta_{2}$ adrenoceptor, Jan Steyaert's lab were using nanobodies to define short lived intermediates in $\beta_{2}$ microglobulin amyloidogenesis [45]. The crystal structure of the amyloidogenic fragment $(\Delta \mathrm{N} 6)$, stabilised by a nanobody, revealed the formation of a domain swapped dimer as a likely early mechanism for self-association. The fibrillogenesis-blocking antibody fragment trapped a new, two-stranded antiparallel $\beta$-sheet, providing detailed insight into the possible initiation of the amyloid process and protein deposition, with implications for therapeutic intervention in dialysis-related amyloidosis. The same nanobody was used in a later study [46] to support crystallography of another variant of $\beta_{2}$ microglobulin (P32G) as a monomer. This revealed an additional, important cis to trans isomerisation event at proline 32 playing a key role in the early onset of $\beta_{2}$ microglobulin amyloid formation.

Misfolding of the pre-synaptic protein, $\alpha$-synuclein, into fibrillar aggregates has been associated with formation of Lewy bodies in Parkinson's disease, but critical, oligomeric precursors have yet to be well defined. Nanobodies are helping to characterise early events in amyloid formation by serving as molecular probes in defining conformations of $\alpha$-synuclein, which may be amenable to therapeutic intervention [47]. Antibody-revealed structural variation within the C-terminal domain, compatible with compaction, suggested a role in stabilization or rearrangement of protofilaments during fibril assembly.

Similarly accumulation and deposition of beta amyloid (A $\beta$ ) fibrils is a well characterised feature of Alzheimer's disease, and the importance of small, soluble oligomeric aggregates as a toxic component in the early stages is increasingly recognised. Single domain camelid antibody fragments, which inhibited formation of mature fibrils [48], inhibited aggregation and extracellular toxicity [49], and which stabilised small, non-toxic A $\beta$ species [50-52] have been described. These antibody fragments do not recognise monomeric or fibrillar forms of $A \beta$, defining previously unknown, critical, early conformations, which hold promise for therapeutic targeting.

In an interesting application for the antibody fragment scaffold, small amyloidogenic peptides (6-10 residues) from $\mathrm{A} \beta$ have been grafted into the CDR3 loop of a VH domain. The resulting 'gammabodies' prevented amyloid formation by stabilising benign intermediates and preventing further aggregation [53]. The CDR3 loop from a shark Ig new antigen receptor (IgNAR) scaffold has also been used to present amylogenic residues $18-41$ of the $A \beta$ peptide for crystallography [54].

In prion diseases, such as Creutzfeldt-Jakob disease (CJD), conversion of the ubiquitous cellular $\operatorname{PrP}^{\mathrm{C}}$ into a misfolded oligomeric conformation, $\mathrm{PrP}^{\mathrm{SC}}$ is a critical event, involving the intrinsically flexible $\mathrm{N}$ terminal region. The crystal structure of full length PrP has been solved in complex with a nanobody, which inhibited prion propogation [55], and revealed $\beta$-enrichment in the palindromic motif (AGAAAAGA) as an early event in conversion of $\operatorname{PrP}^{\mathrm{C}}$ to $\operatorname{PrP}^{\mathrm{SC}}$. The authors go on to comment that such structures are amenable to soaking experiments to study interactions of potential small molecules with the flexible part of PrP, linking a nanobody-stabilised conformation with discovery of new chemical entities. 


\section{Enzyme Systems—Links to Kinetics}

Allosteric switch mechanisms in enzymes have been revealed in structural studies with antibody fragments. For example the Fab fragment of an antibody, which inhibited the catalytic activity of the trypsin-like serine protease hepatocyte growth factor activator (HGFA), trapped a conformational change featuring partial collapse and reorganisation of subsites, incompatible with substrate binding [56]. The potential for linking dynamic transition between conformational states to kinetics has also been highlighted with synthetic Fab fragments preferentially binding the maltose-bound conformation of the maltose-binding protein (MBP) and acting as positive allosteric modulators [57].

Studies on active-site trapping with an antibody fragment of the Escherichia coli enzyme dihydrofolate reductase (DHFR) have revealed a nanobody, which binds simultaneously to enzyme and substrate, causing a twenty-fold reduction in the rate of folate exchange kinetics. This interesting observation opens up new, generalizable avenues for antibody-based inhibitors of enzymes and receptors [58]. Of particular interest to this review, the same group reported earlier [59] that allosteric effects, brought about by binding of antibody fragments, were due to conformational constraint and altered protein dynamics rather than epitope distortion, suggesting that the antibody fragments were locking out naturally sampled conformations rather than imposing unnatural perturbation.

\section{Techniques}

Antibody-fragment definition of biologically relevant conformations of target proteins offer advantages over structural studies with engineered, constitutively active mutant forms of proteins, such

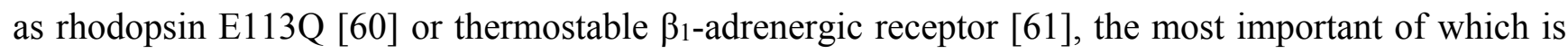
that the native protein is being studied, and the conformations adopted are likely to be naturally sampled.

In addition to X-ray crystallography, NMR spectroscopy has been used to study the conformational equilibrium and transmembrane region diversity in the inverse agonist-bound, neutral antagonist-bound, partial agonist-bound and full agonist-bound states of the $\beta_{2}$ adrenoceptor [18,62-64]. Rotationallyaligned NMR, which is well suited to the study of membrane proteins in liquid crystalline phospholipid bilayers, and amenable to antibody fragment-stabilisation, has been applied to the IL-8 receptor CXCR1 [65].

Data from isothermal calorimetry (ITC) and quartz crystal microbalance have been used to follow changes in affinities of VHH fragments binding to $\alpha$-synuclein during fibril assembly and maturation [47]. Decrease in affinity for fibrils compared to monomers suggested that the conformation or accessibility of the C-terminal domain changed on fibril formation. When matched to epitope data from HSQC NMR studies, areas of the $\alpha$-synuclein molecule responsible for the early stages of fibrillation could be pinpointed.

An emerging technique, which is beginning to contribute to our understanding of conformational change, and which is amenable to antibody fragment technology, is Double Electron-Electron Resonance (DEER), in which distance changes between pairs of nitroxide side chains introduced at specific, solvent-exposed locations on target proteins are measured. The technique has been applied to high resolution distance mapping of helices in rhodopsin [66], and complements X-ray crystallography in that the protein is observed from solution, free from the structural constraints imposed during the crystallisation process. 
Antibody fragment-defined structures provide fundamental starting points for molecular dynamics simulations, and application to the interaction between $\beta_{2}$ adrenoceptor and Gs confirmed equilibration in only $6 \mathrm{~ns}$ when starting from the nanobody-bound state [67]. Computational removal of the nanobody from the active conformation revealed further dynamic processes, intermediate states [68] and a structural basis for the activation mechanism. Such molecular dynamics simulations are becoming increasingly important in drug discovery, providing valuable insight into previously unknown conformations of target proteins. Structures derived from different function-modifying antibody fragment-stabilised complexes establish critical wet lab foundation for these studies.

\section{Derivation of Antibody Fragments}

Many of the antibody variable regions described in papers cited in this review have been derived from phage libraries [69], and detailed protocols for obtaining conformation-selective Fab antibody fragments [70] and single domain VHH nanobodies [71] have been published. In addition, synthetic libraries, such as the recently published CDR-H3 library [72] are likely to provide a future source of interesting variable regions for this application. Covalent probes have been used to trap the caspase protease in 'on' and 'off' forms to enable alternating rounds of selection and anti-selection for Fab fragments displayed on phage [73].

Many of the most informative antibody fragments are very rare in immune repertoires or libraries, and methods with proven capability to mine these immune repertoires efficiently offer an advantage. Cloning variable region sequences from selected, single B cells is a powerful technique in this regard, with proven capacity to discover one function-modifying antibody among $3 \times 10^{9} \mathrm{~B}$ cells [74].

Patient autoantibodies also provide a promising and largely untapped source of B cells, with the promise of exquisite specificity. A disease-related antiserum, which functions as an allosteric modulator for the calcium-sensing receptor, was recovered from an acquired hypocalciuric hypercalcemia patient and shown to maintain the GPCR in an active, Gq-receptive conformation with its agonist [75]. Interrogation of such patient B cell repertoires to isolate the appropriate monoclonal antibodies using single B cell cloning [74] offers the intriguing prospect of structurally defining biologically relevant conformations of target proteins with clinical validation.

Of particular note are recent developments in antibody discovery, based on rational, structure-based, de novo design [76], which will soon offer the exciting prospect of making antibodies to computationally-predicted intermediate, or relatively sparsely populated conformations of target proteins, circumventing the challenge of actually having to make and stabilise those conformations in the wet lab. Such de novo-designed antibody fragments will enable small molecule screening against previously undefined, but biologically critical, conformations of target proteins and provide exciting, new opportunities for drug discovery.

\section{The Future}

In this mode, antibody fragments are building on a research base defining biologically relevant conformations of target proteins, grounding molecular dynamics simulations in wet lab biochemistry and providing exciting opportunities for innovative drug discovery. The ability to visualise, and subsequently screen against, antibody fragment-defined, biologically relevant conformations of 
proteins [77] ushers in a new era of drug discovery, paving the way for new generations of first in class drugs, to bring new benefits to patients.

\section{Acknowledgements}

I would like to acknowledge valuable discussions with colleagues at UCB.

\section{Conflicts of Interest}

ADGL holds shares and share options in UCB.

\section{References}

1. Griffin, L.; Lawson, A.D.G. Antibody fragments as tools in crystallography. Clin. Exp. Immunol. 2011, 165, 285-291.

2. Air, G.M.; Webster, R.G.; Colman, P.M.; Laver, W.G. Distribution of sequence differences in influenza N9 neuraminidase of tern and whale viruses and crystallization of the whale neuraminidase complexed with antibodies. Virology 1987, 160, 346-354.

3. Ostermeier, C.; Iwata, S.; Ludwig, B.; Michel, H. Fv fragment-mediated crystallization of the membrane protein bacterial cytochrome $c$ oxidase. Nat. Struct. Biol. 1995, 2, 842-846.

4. Loris, R.; Marianovsky, I.; Lah, J.; Laeremans, T.; Engelberg-Kulka, H.; Glaser, G.; Muyldermans, S.; Wyns, L. Crystal structure of the intrinsically-flexible addiction antidote MazE. J. Biol. Chem. 2003, 278, 28252-28257.

5. Hassaine, G.; Deluz, C.; Grasso, L.; Wyss, R.; Tol, M.B.; Hovius, R.; Graff, A.; Stahlberg, H.; Tomizaki, T.; Desmyter, A.; et al. X-ray structure of the mouse serotonin 5- $\mathrm{HT}_{3}$ receptor. Nature 2014, 512, 276-281.

6. Ramnath Pathare, G.; Nagy, I.; Śledź, P.; Anderson, D.J.; Zhou, H.-J.; Pardon, E.; Steyaert, J.; Förster, F.; Bracher, A.; Baumeister, W. Crystal structure of the proteasomal deubiquitylation module Rpn8-Rpn11. Proc. Natl. Acad. Sci. USA 2014, 111, 2984-2989.

7. Prongay, A.J.; Smith, T.J.; Rossmann, M.G.; Ehrlich, L.S.; Carter, C.A.; McClure, J. Preparation and crystallization of a human immunodeficiency virus p24-Fab complex. Proc. Natl. Acad. Sci. USA 1990, 87, 9980-9984.

8. Baranova, E.; Fronzes, R.; Garcia-Pino, A.; Van Gerven, N.; Papapostolou, D.; Péhau-Arnaudet, G.; Pardon, E.; Steyaert, J.; Howorka, S.; Remaut, H. SbsB structure and lattice reconstruction unveil $\mathrm{Ca}^{2+}$ triggered S-layer assembly. Nature 2012, 487, 119-122.

9. Löw, C.; Yau, Y.H.; Pardon, E.; Jegerschöld, C.; Wåhlin, L.; Quistgaard, E.M.; Moberg, P.; Geifman-Shochat, S.; Steyaert, J.; Nordlund, P. Nanobody mediated crystallization of an archeal mechanosensitive channel. PLoS One 2013, 8, e77984.

10. Tereshko, V.; Uysal, S.; Koide, A.; Margalef, K.; Koide, S.; Kossiakoff, A.A. Toward chaperoneassisted crystallography: protein engineering enhancement of crystal packing and X-ray phasing capabilities of a camelid single-domain antibody $\left(\mathrm{V}_{\mathrm{HH}}\right)$ scaffold. Protein Sci. 2008, 17, 1175-1187.

11. Zhou, Y.; Morais-Cabral, J.H.; Kaufman, A.; MacKinnon, R. Chemistry of ion coordination and hydration revealed by a $\mathrm{K}^{+}$channel-Fab complex at $2.0 \AA$ resolution. Nature 2001, 414, 43-48. 
12. Ghanouni, P.; Gryczynski, Z.; Steenhuis, J.J.; Weon Lee, T.; Farrens, D.L.; Lakowicz, J.R.; Kobilka, B.K. Functionally different agonists induce distinct conformations in the G protein coupling domain of the $\beta_{2}$ adrenergic receptor. J. Biol. Chem. 2001, 276, 24433-24436.

13. Rosenbaum, D.M.; Cherezov, V.; Hanson, M.A.; Rasmussen, S.G.F.; Thian, F.S.; Kobilka, T.S.; Choi, H.-J.; Yao, X.-J.; Weis, W.I.; Stevens, R.C.; et al. GPCR engineering yields high-resolution structural insights into $\beta_{2}$-adrenergic receptor function. Science 2007, 318, 1266-1273.

14. Rasmussen, S.G.F.; Choi, H.-J.; Rosenbaum, D.M.; Kobilka, T.-S.; Thian, F.S.; Edwards, P.C.; Burghammer, M.; Ratnala, V.R.P.; Sanishvili, R.; Fischetti, R.F.; et al. Crystal structure of the human $\beta_{2}$ adrenergic G-protein-coupled receptor. Nature 2007, 450, 383-387.

15. Uysal, S.; Vásquez, V.; Tereshko, V.; Esaki, K.; Fellouse, F.A.; Sidhu, S.S.; Koide, S.; Perozo, E.; Kossiakoff, A. Crystal structure of full length KcsA in its closed conformation. Proc. Natl. Acad. Sci. USA 2009, 106, 6644-6649.

16. Manglik, A.; Kobilka, B. The role of protein dynamics in GPCR function: Insights from the $\beta_{2} A R$ and rhodopsin. Curr. Opin. Cell Biol. 2014, 27, 136-143.

17. Kahsai, A.W.; Xiao, K.; Rajagopal, S.; Ahn, S.; Shukla, A.K.; Sun, J.; Oas, T.G.; Lefkowitz, R.J. Multiple ligand-specific conformations of the $\beta_{2}$-adrenergic receptor. Nat. Chem. Biol. 2011, 7 , 692-700.

18. Nygaard, R.; Zou, Y.; Dror, R.O.; Mildorf, T.J.; Arlow, D.H.; Manglik, A.; Pan, A.C.; Liu, C.W.; Fung, J.J.; Bokoch, M.P.; et al. The dynamic process of $\beta_{2}$-adrenergic receptor activation. Cell 2013, 152, 532-542.

19. Deupi, X.; Kobilka, B.K. Energy landscapes as a tool to integrate GPCR structure, dynamics and function. Physiology 2010, 25, 293-303.

20. Steyaert, J.; Kobilka, B.K. Nanobody stabilization of G protein-coupled receptor conformational states. Curr. Opin. Struct. Biol. 2011, 21, 567-572.

21. Webb, D.R.; Handel, T.M.; Kretz-Rommel, A.; Stevens, R.C. Opportunities for functional selectivity in GPCR antibodies. Biochem. Pharm. 2013, 85, 147-152.

22. Takao, M.; Iwasa, T.; Yamamoto, H.; Takeuchi, T; Tokunaga, F. Anti-bovine rhodopsin monoclonal antibody recognising light-dependent structural change. Zoolog. Sci. 2002, 19, 651-659.

23. Gupta, A.G.; Décaillot, F.M.; Gomes, I.; Tkalych, O.; Heimann, A.S.; Ferro, E.S.; Devi, L.A. Conformation state-sensitive antibodies to G-protein-coupled receptors. J. Biol. Chem. 2007, 282, 5116-5124.

24. Banner, D.W.; Gsell, B.; Benz, J.; Bertschinger, J.; Burger, D.; Brack, S.; Cuppuleri, S.; Debulpaep, M.; Gast, A.; Grabulovski, D.; et al. Mapping the conformational space accessible to BACE2 using surface mutants and cocrystals with Fab fragments, fynomers and xaperones. Acta Crystallogr. D 2013, D69, 1124-1137.

25. Rasmussen, S.G.F.; Choi, H.-J.; Fung, J.J.; Pardon, E.; Casarosa, P.; Chae, P.S.; DeVree, B.T.; Rosenbaum, D.M.; Thian, F.S.; Kobilka, T.S.; et al. Structure of a nanobody-stabilized active state of the $\beta_{2}$ adrenoceptor. Nature 2011, 469, 175-180.

26. Rosenbaum, D.M.; Zhang, C.; Lyons, J.A.; Holl, R.; Aragao, D.; Arlow, D.H.; Rasmussen, S.G.F.; Choi, H.-J.; DeVree, B.T.; Sunahara, R.K.; et al. Structure and function of an irreversible agonist$\beta_{2}$ adrenoceptor complex. Nature 2011, 469, 236-240. 
27. Rasmussen, S.G.F.; DeVree, B.T.; Zou, Y.; Kruse, A.C.; Chung, K.Y.; Kobilka, T.S.; Thian, F.S.; Chae, P.S.; Pardon, E.; Calinski, D.; et al. Crystal structure of the $\beta_{2}$ adrenergic receptor-Gs protein complex. Nature 2011, 477, 549-555.

28. Hino, T.; Arakawa, T.; Iwanari, H.; Yurugi-Kobayashi, T.; Ikeda-Suno, C.; Nakada-Nakura, Y.; Kusano-Arai, O.; Weyand, S.; Shimamura, T.; Nomura, N.; et al. G-protein-coupled receptor inactivation by an allosteric inverse-agonist antibody. Nature 2012, 482, 237-240.

29. Drinkwater, N.; Cossins, B.P.; Keeble, A.H.; Wright, M.; Cain, K.; Hailu, H.; Oxbrow, A.; Delgado, J.; Shuttleworth, L.K.; Kao, M.W.-P.; et al. Human immunoglobulin E flexes between acutely bent and extended conformations. Nat. Struct. Mol. Biol. 2014, 21, 397-404.

30. Kane Dickson, V.; Pedi, L.; Long, S.B. Structure and insights into the function of a $\mathrm{Ca}^{2+}$-activated $\mathrm{Cl}^{-}$channel. Nature 2014, doi:10.1038/nature13913.

31. De Clercq, S.; Zwaenepoel, O.; Martens, E.; Vandekerckhove, J.; Guillabert, A.; Gettemans, J. Nanobody-induced perturbation of LFA-1/L-plastin phosphorylation impairs MTOC docking, immune synapse formation and T cell activation. Cell. Mol. Life Sci. 2013, 70, 909-922.

32. Kruse, A.C.; Ring, A.M.; Manglik, A.; Hu, J.; Hu, K.; Eitel, K.; Hübner, H.; Pardon, E.; Valant, C.; Sexton, P.M.; et al. Activation and allosteric modulation of a muscarinic acetylcholine receptor. Nature 2013, 504, 101-106.

33. Kruse, A.C.; Kobilka, B.K.; Gautam, D.; Sexton, P.M.; Christopoulos, A.; Wess, J. Muscarinic acetylcholine receptors: Novel opportunities for drug development. Nat. Rev. Drug Discov. 2014, 13, 549-560.

34. Koth, C.M.; Murray, J.M.; Mukund, S.; Madjidi, A.; Minn, A.; Clarke, H.J.; Wong, T.; Chiang, V.; Luis, E.; Estevez, A.; et al. Molecular basis for negative regulation of the glucagon receptor. Proc. Natl. Acad. Sci. USA 2012, 109, 14393-14398.

35. Schmitz, K.R.; Bagchi, A.; Roovers, R.C.; van Bergen en Henegouwen, P.M.P.; Ferguson, K.M. Structural evaluation of EGFR inhibition mechanisms for nanobodies/VHH domains. Structure 2013, 21, 1214-1224.

36. Ward, A.B.; Szewczyk, P.; Grimard, V.; Lee, C.-W.; Martinez, L.; Doshi, R.; Caya, A.; Villaluz, M.; Pardon, E.; Cregger, C.; et al. Structures of P-glycoprotein reveal its conformational flexibility and an epitope on the nucleotide-binding domain. Proc. Natl. Acad. Sci. USA 2013, 110, 13386-13391.

37. Staus, D.P.; Wingler, L.M.; Strachan, R.T.; Rasmussen, S.G.F.; Pardon, E.; Ahn, S.; Steyaert, J.; Kobilka, B.K.; Lefkowitz, R.J. Regulation of $\beta_{2}$-adrenergic receptor function by conformationally selective single-domain intrabodies. Mol. Pharm. 2014, 85, 472-481.

38. Irannejad, R.; Tomshine, J.C.; Tomshine, J.R.; Chevalier, M.; Mahoney, J.P.; Steyaert, J.; Rasmussen, S.G.F.; Sunahara, R.K.; El-Samad, H.; Huang, B.; et al. Conformational biosensors reveal GPCR signalling from endosomes. Nature 2013, 495, 534-538.

39. Haque, A.; Andersen, J.N.; Salmeen, A.; Barford, D.; Tonks, N.K. Conformation-sensing antibodies stabilise the oxidised form of PTP1B and inhibit its phosphatase activity. Cell 2011, 147, 185-198.

40. Vercruysse, T.; Boons, E.; Venken, T.; Vanstreels, E.; Voet, A.; Steyaert, J.; De Maeyer, M.; Daelemans, D. Mapping the binding interface between an HIV-1 inhibiting intrabody and the viral protein Rev. PLoS One 2013, 8, e60259. 
41. Khamrui, S.; Turley, S.; Pardon, E.; Steyaert, J.; Fan, E.; Verlinde, C.L.M.J.; Bergman, L.W.; Hol, W.G.J. The structure of the D3 domain of Plasmodium falciparum myosin tail interacting protein MTIP in complex with a nanobody. Mol. Biochem. Parasitol. 2013, 190, 87-91.

42. Chaikuad, A.; Keates, T.; Vincke, C.; Kaufholz, M.; Zenn, M.; Zimmermann, B.; Gutiérrez, C.; Zhang, R.-G.; Hatzos-Skintges, C.; Joachimiak, A.; et al. Structure of cyclin G-associated kinase (GAK) trapped in different conformations using nanobodies. Biochem. J. 2014, 459, 59-69.

43. McLellan, J.S.; Chen, M.; Leung, S.; Graepel, K.W.; Du, X.; Yang, Y.; Zhou, T.; Baxa, U.; Yasuda, E.; Beaumont, T.; et al. Structure of RSV fusion glycoprotein trimer bound to a prefusion-specific neutralising antibody. Science 2013, 340, 1113-1117.

44. Dumoulin, M.; Last, A.M.; Desmyter, A.; Decanniere, K.; Canet, D.; Larsson, G.; Spencer, A.; Archer, D.B.; Sasse, J.; Muyldermans, S.; et al. A camelid antibody fragment inhibits the formation of amyloid fibrils by human lysozyme. Nature 2003, 424, 783-788.

45. Domanska, K.; Vanderhaegen, S.; Srinivasan, V.; Pardon, E.; Dupeux, F.; Marquez, J.A.; Giorgetti, S.; Stoppini, M.; Wyns, L.; Bellotti, V.; et al. Atomic structure of a nanobody-trapped domainswapped dimer of an amyloidogenic $\beta 2$-microglobulin variant. Proc. Natl. Acad. Sci. USA 2011, 108, 1314-1319.

46. Vanderhaegen, S.; Fislage, M.; Domanska, K.; Versées, W.; Pardon, E.; Bellotti, V.; Steyaert, J. Structure of an early native-like intermediate of B2-microglobulin amyloidogenesis. Protein Sci. 2013, 22, 1349-1357.

47. Guilliams, T.; El-Turk, F.; Buell, A.K.; O’Day, E.M.; Aprile, F.A.; Esbjörner, E.K.; Vendruscolo, M.; Cremades, N.; Pardon, E.; Wyns, L.; et al. Nanobodies raised against monomeric $\alpha$-synuclein distinguish between fibrils at different maturation stages. J. Mol. Biol. 2013, 425, 2397-2411.

48. Habicht, G.; Haupt, C.; Friedrich, R.P.; Hortschansky, P.; Sachse, C.; Meinhardt, J.; Wieligmann, K.; Gellerman, G.P.; Brodhun, M.; Götz, J.; et al. Directed selection of a conformational antibody domain that prevents mature amyloid fibril formation by stabilizing A $\beta$ profibrils. Proc. Natl. Acad. Sci. USA 2007, 104, 19232-19237.

49. Zameer, A.; Kasturirangan, S.; Emadi, S.; Nimmagadda, S.V.; Sierks, M.R. Anti-oligomeric A $\beta$ single chain variable domain antibody blocks $A \beta$-induced toxicity against human neuroblastoma cells. J. Mol. Biol. 2008, 384, 917-928.

50. Lafaye, P.; Achour, I.; England, P.; Duyckaerts, C.; Rougeon, F. Single-domain antibodies recognize selectively small oligomeric forms of amyloid $\beta$, prevent $A \beta$-induced neurotoxicity and inhibit fibril formation. Mol. Immunol. 2009, 46, 695-704.

51. Morgado, I.; Wieligman, K.; Bereza, M.; Rönicke, R.; Meinhardt, K.; Annamalai, K.; Baumann, M.; Wacker, J.; Hortschansky, P.; Malešević, M.; et al. Molecular basis of $\beta$-amyloid oligomer recognition with a conformational antibody fragment. Proc. Natl. Acad. Sci. USA 2012, 109, 12503-12508.

52. Kasturirangan, S.; Li, L.; Emadi, S.; Boddapati, S.; Schulz, P.; Sierks, M.R. Nanobody specific for oligomeric beta-amyloid stabilizes nontoxic form. Neurobiol. Aging 2012, 33, 1320-1328.

53. Ladiwala, A.R.A.; Bhattacharya, M.; Perchiacca, J.M.; Cao, P.; Raleigh, D.P.; Abedini, A.; Schmidt, A.M.; Varkey, J.; Langen, R.; Tessier, P.M. Rational design of potent domain antibody inhibitors of amyloid fibril assembly. Proc. Natl. Acad. Sci. USA 2012, 109, 19965-19970. 
54. Streltsov, V.A.; Varghese, J.N.; Masters, C.L.; Nuttall, S.D. Crystal structure of the amyloid- $\beta$ p3 fragment provides a model for oligomer formation in Alzheimer's disease. J. Neurosci. 2011, 31, 1419-1426.

55. Abskharon, R.N.N.; Giachin, G.; Wohlkonig, A.; Soror, S.H.; Pardon, E.; Legname, G.; Steyaert, J. Probing the N-terminal $\beta$-sheet conversion in the crystal structure of the human prion protein bound to a nanobody. J. Am. Chem. Soc. 2014, 136, 937-944.

56. Ganesan, R.; Eigenbrot, C.; Wu, Y.; Liang, W.C.; Shia, S.; Lipari, M.T.; Kirchhofer, D. Unravelling the allosteric mechanism of serine protease inhibition by an antibody. Structure 2009, 17, 1614-1624.

57. Rizk, S.S.; Paduch, M.; Heithaus, J.H.; Duguid, E.M.; Sandstrom, A.; Kossiakoff, A.A. Allosteric control of ligand-binding affinity using engineered conformation-specific effector proteins. Nat. Struct. Mol. Biol. 2011, 18, 437-442.

58. Oyen, D.; Steyaert, J.; Barlow, J.N. Inhibition of ligand exchange kinetics via active-site trapping with an antibody fragment. Biochemistry 2014, 53, 1879-1881.

59. Oyen, D.; Wechselberger, R.; Srinivasan, V.; Steyaert, J.; Barlow, J.N. Mechanistic analysis of allosteric and non-allosteric effects arising from nanobody binding to two epitopes of the dihydrofolate reductase of Escherichia coli. Biochim. Biophys. Acta 2013, 1834, 2147-2157.

60. Standfuss, J.; Edwards, P.C.; D’Antona, A.; Fransen, M.; Xie, G.; Oprian, D.D.; Schertler, G.F.X. Crystal structure of constitutively active rhodopsin: How an agonist can activate its GPCR. Nature 2011, 471, 656-660.

61. Moukhametzianov, R.; Warne, T.; Edwards, P.C.; Serrano-Vega, M.J.; Leslie, A.G.W.; Tate, C.G.; Schertler, G.F.X. Two distinct conformations of helix 6 observed in antagonist-bound structures of

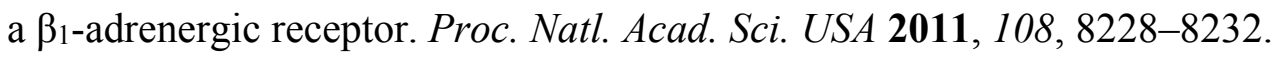

62. Liu, J.J.; Horst, R.; Katritch, V.; Stevens, R.C.; Wüthrich, K. Biased signalling pathways in $\beta_{2}$-adrenergic receptor characterized by ${ }^{19} \mathrm{~F}-\mathrm{NMR}$. Science 2012, 335, 1106-1110.

63. Kofuku, Y.; Ueda, T.; Okude, J.; Shiraishi, Y.; Kondo, K.; Maeda, M.; Tsujishita, H.; Shimada, I. Efficacy of the $\beta_{2}$-adrenergic receptor is determined by conformational equilibrium in the transmembrane region. Nat. Commun. 2012, 3, 1045-1053.

64. Kim, T.H.; Chung, K.Y.; Manglik, A.; Hansen, A.; Dror, R.O.; Mildorf, T.J.; Shaw, D.E.; Kobilka, B.K.; Prosser, R.S. The role of ligands on the equilibria between functional states of a $\mathrm{G}$ proteincoupled receptor. J. Am. Chem. Soc. 2013, 135, 9465-9474.

65. Park, S.H.; Das, B.B.; Casagrande, F.; Tian, Y.; Nothnagel, H.J.; Chu, M.; Kiefer, H.; Maier, K.; De Angelis, A.A.; Marassi, F.M.; et al. Structure of the chemokine receptor CXCR1 in phospholipid bilayers. Nature 2012, 491, 779-783.

66. Altenbach, C.; Kusnetzow, A.K.; Ernst, O.P.; Hofmann, K.P.; Hubbell, W.L. High resolution distance mapping in rhodopsin reveals the pattern of helix movement due to activation. Proc. Natl. Acad. Sci. USA 2008, 105, 7439-7444.

67. Feng, Z.; Hou, T.; Li, Y. Studies on the interactions between $\beta_{2}$ adrenergic receptor and Gs protein by molecular dynamics simulations. J. Chem. Inform. Model. 2012, 52, 1005-1014.

68. Dror, R.O.; Arlow, D.H.; Maragakis, P.; Mildorf, T.J.; Pan, A.C.; Xu, H.; Borhani, D.W.; Shaw, D.E. Activation mechanism of the $\beta_{2}$-adrenergic receptor. Proc. Natl. Acad. Sci. USA 2011, $108,18684-18689$. 
69. Bradbury, A.R.M.; Sidhu, S.; Dübel, S; McCafferty, J. Beyond natural antibodies: The power of in vitro display technologies. Nat. Biotechnol. 2013, 29, 245-254.

70. Paduch, M.; Koide, A.; Uysal, S.; Rizk, S.S.; Koide, S.; Kossiakoff, A.A. Generating conformationspecific synthetic antibodies to trap proteins in selected functional states. Methods 2013, 60, 3-14.

71. Pardon, E.; Laeremans, T.; Triest, S.; Rasmussen, S.G.F.; Wohlkönig, A.; Ruf, A.; Muyldermans, S.; Hol, W.G.J.; Kobilka, B.K.; Steyaert, J. A general protocol for the generation of nanobodies for structural biology. Nat. Protoc. 2014, 9, 674-693.

72. Mahon, C.M.; Lambert, M.A.; Glanville, J.; Wade, J.M.; Fennell, B.J.; Krebs, M.R.; Armellino, D.; Yang, S.; Liu, X.; O'Sullivan, C.M.; et al. Comprehensive interrogation of a minimalist synthetic CDR-H3 library and its ability to generate antibodies with therapeutic potential. J. Mol. Biol. 2013, $425,1712-1730$.

73. Gao, J.; Sidhu, S.S.; Wells, J.A. Two-state selection of conformation-specific antibodies. Proc. Natl. Acad. Sci. USA 2009, 106, 3071-3076.

74. Tickle, S.; Adams, R.; Brown, D.; Griffiths, M.; Lightwood, D.; Lawson, A. High-throughput screening for high affinity antibodies. J. Lab. Autom. 2009, 14, 303-307.

75. Makita, N.; Sato, J.; Manaka, K.; Shoji, Y.; Oishi, A.; Hashimoto, M.; Fujita, T.; Iiri, T. An acquired hypocalciuric hypercalcemia autoantibody induces allosteric transition among active human Ca-sensing receptor conformations. Proc. Natl. Acad. Sci. USA 2007, 104, 5443-5448.

76. Schreiber, G.; Fleishman, S.J. Computational design of protein-protein interactions. Curr. Opin. Struct. Biol. 2013, 23, 903-910.

77. Lawson, A.D.G. Antibody-enabled small molecule drug discovery. Nat. Rev. Drug Discov. 2012, $11,519-525$.

(C) 2014 by the authors; licensee MDPI, Basel, Switzerland. This article is an open access article distributed under the terms and conditions of the Creative Commons Attribution license (http://creativecommons.org/licenses/by/4.0/). 